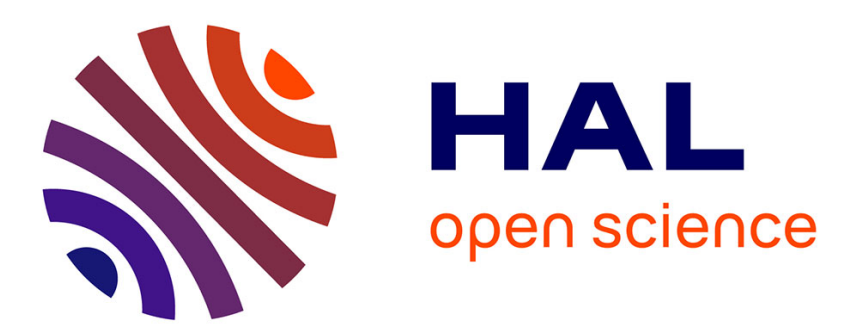

\title{
Interactions between solidification and fluid flow. Effects on cast structures and segregations
}

\author{
G. Lesoult, H. Combeau, M. Moukassi
}

\section{To cite this version:}

G. Lesoult, H. Combeau, M. Moukassi. Interactions between solidification and fluid flow. Effects on cast structures and segregations. Journal de Physique IV Proceedings, 1993, 03 (C7), pp.C7-813-C7822. 10.1051/jp4:19937128 . jpa-00251747

\section{HAL Id: jpa-00251747 https://hal.science/jpa-00251747}

Submitted on 1 Jan 1993

HAL is a multi-disciplinary open access archive for the deposit and dissemination of scientific research documents, whether they are published or not. The documents may come from teaching and research institutions in France or abroad, or from public or private research centers.
L'archive ouverte pluridisciplinaire HAL, est destinée au dépôt et à la diffusion de documents scientifiques de niveau recherche, publiés ou non, émanant des établissements d'enseignement et de recherche français ou étrangers, des laboratoires publics ou privés. 


\title{
Interactions between solidification and fluid flow. Effects on cast structures and segregations
}

\author{
G. LESOULT, H. COMBEAU and M. MOUKASSI ${ }^{*}$ \\ Ecole des Mines de Nancy, Parc de Saurupt, 54042 Nancy cedex, France \\ * UNIMETAL Recherche, 57360 Amneville, France
}

\begin{abstract}
$\underline{\text { Abstract }}$
Natural or forced fluid flow of the bulk melt can induce several changes in the solidification history of a casting : it may change the heat transfer conditions, the as-cast grain distribution, and the segregations. On the other hand, solidification can result in intense fluid flow due to natural solutal convection and in severe local segregations.

The two following practical cases illustrate the variety and complexity of interactions between the fluid flow and the solidification of alloys :

- the effects of the stirring of the bulk liquid on the formation of the equiaxed zone during the continuous casting of steels,

- the formation of freckles and related segregations during the directional solidification of nickel-base alloys.

Informations are given about, either new experimental observations, or up-dated physical and numerical models related to each case chosen here as examples.

In the case of the influence of stirring on the formation of the equiaxed zone, emphasis is put on the importance of the interaction of the fluid flow with the dendrites in the columnar zone and in the stirred region itself. In the case of the freckles, evidence is brought forward that the dendritic nature and structure of the mushy zone are not the only causes of the dependence of the freckling on the heat transfer conditions during directional solidification.
\end{abstract}

\section{INTRODUCTION}

Natural or forced fluid flow of the bulk melt or of the pasty solidifying alloy can induce several changes in the solidification history of the metal : it may change the heat transfer conditions, the as-cast grain distribution, and the segregations.

Convection, forced or natural, is known since many decades for interfering with solidification in various conventional solidification processes, as illustrated by the following examples. The initial superheat imposed during casting of steel ingots results in a definite thermal natural convection during the first stage of the development of the columnar zone and in the deflection of the columnar grains. Mechanical stirring is used, since many decades too, to control the chemical homogeneity of the single crystals grown by the Czochralsky method. More recently, electromagnetic stirring was introduced on an industrial basis to improve the quality of continuously cast products, either in the steel or in the aluminium industry. Finally, stirring, either mechanical or electromagnetic, is increasingly used also to produce non dendritic cast materials. 
On the other hand, solidification can result in intense fluid flow through natural solutal convection, in severe local segregations (freckles or A segregates for instance), in rearrangements of grain structure, and in macrosegregation.

The well-known facts which have been reminded here result from more or less intimate interactions between solidification and fluid flow at two or three different length scales : the scale of the product as far as heat and momentum transfers are concerned, the scale of the dendrite as far as microsegregation and local dendrite arm remelting are concerned, may be an intermediate scale as far as fluid flow instabilities in the mushy zone are concerned.

The aim of this paper is to present and to discuss a few results related to the following two situations :

- the effects of liquid stirring on the formation of the equiaxed zone during the continuous casting of steel,

- the formation of freckles and related segregations during the directional solidification of nickel base alloys.

Indeed, these examples can bring better to light the nature of some elementary phenomena resulting in complex interactions between solidification and fluid flow.

\section{USE OF THE ELECTROMAGNETIC STIRRING DURING THE CONTINUOUS CASTING OF STEEL}

Continuous casting $(\mathrm{CC})$ is now the preferred technique for solidifying liquid steel in the Iron and Steel industry. Columnar solidification is the normal solidification mode which is obtained with standard $\mathrm{CC}$ techniques. It provides satisfactory properties across the section of the product, except in the central

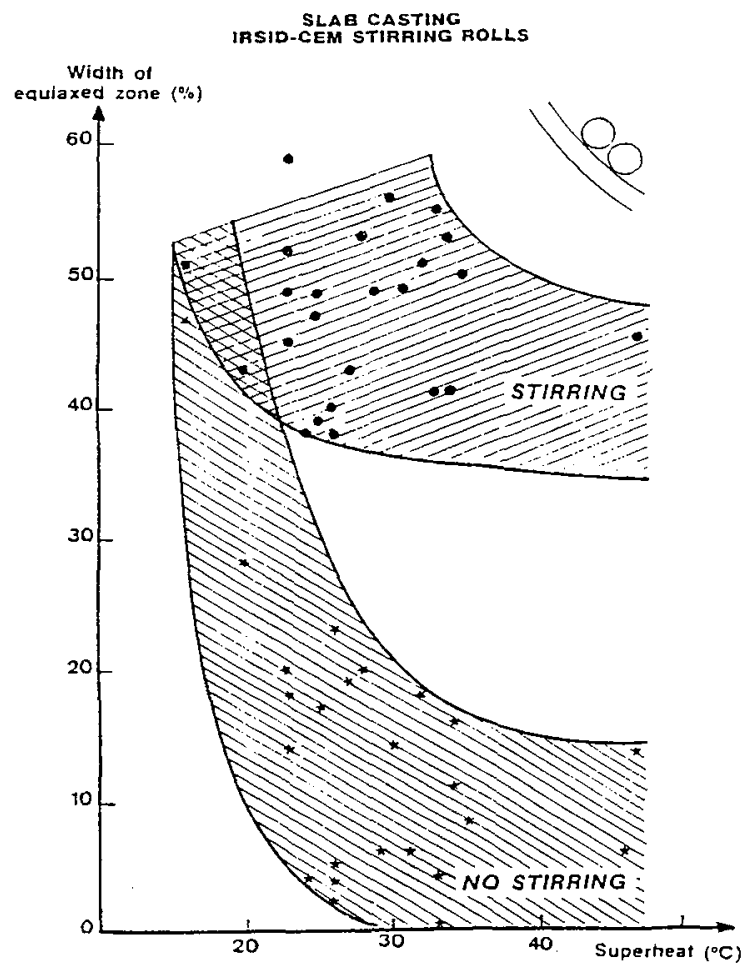

Fig. 1 : Influence of superheat in tundish on width of equiaxed zone with and without EMS (from Ref. [2]) : solid circles : with EMS ; solid stars : without EMS. 
region where unusually high solute contents are sometimes observed. In order to prevent such drawback, the continuous casting operator uses a series of techniques which impede columnar solidification and replace it by equiaxed solidification. Low temperature casting is the cheapest technique available to reach that goal, but it is difficult to use in practice with a good reliability because superheats lower than $10 \mathrm{~K}$ should often be aimed at to obtain $50 \%$ of equiaxed structure as shown in Fig 1 . Another very versatile technique available is electromagnetic stirring (EMS), several technologies of which have been developed for the case of bloom and slab continuous casting [1,2]. It is shown in Fig. 1 how EMS increases the width of equiaxed zone for slabs, when cast with a high superheat and, therefore, how it decreases the influence of the superheat on this width.

If adequate scholarly attention has been devoted to columnar solidification, this is not the case with equiaxed solidification especially when it is promoted by stirring. In order to help to rectify this lack several simple models of equiaxed solidification during continuous casting have been developed $[3,4]$. Simultaneously, specific experiments were carried out in order to observe various effects of stirring on the structure of both the columnar and the equiaxed zones [5-9].

EXPERIMENTAL STUDY OF THE EFFECTS OF STIRRING ON THE FORMATION OF THE EQUIAXED ZONE

Several studies were carried out according to the principles of experiments which where conceived firstly by Takahashi et al. $[10,11]$. The melt is contained in a long cylindrical crucible of radius $R_{1}$. A second concentric cylinder of smaller radius $R_{0}$ is plunged in the melt ; it is water-cooled so

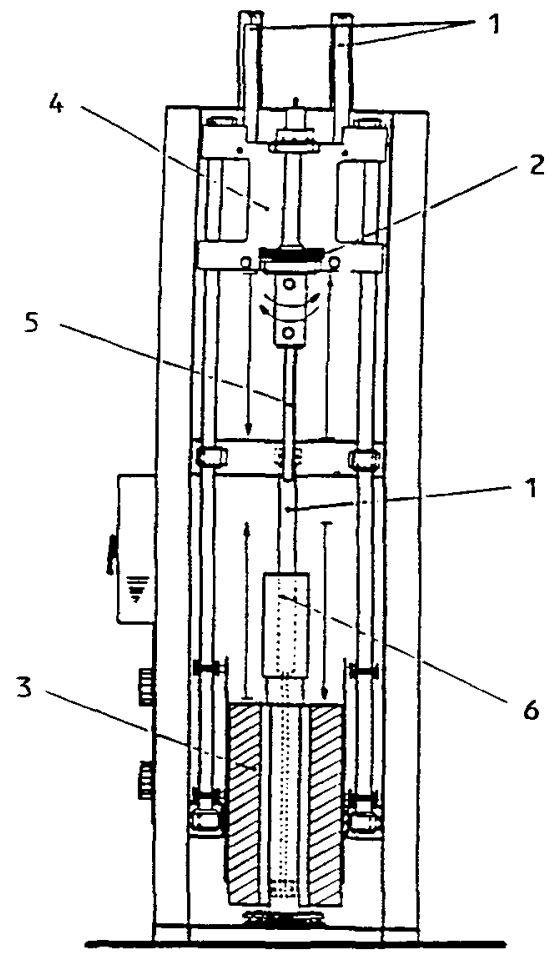

Fig.2 : Experimental set-up for melting, solidifying, stirring and quenching low melting point alloys. 1 . pneumatic jacks; 2 . stirring device; 3 . removable wire furnace; 4 . fast moving stirring and quenching unit; 5. stirrer: hollow water cooled cylinder; 6 . crucible. 
that the solidification of the melt proceeds radially on the inner cylinder from the center towards the outer side. Morever this cylinder can rotate. Therefore the molten alloy can be set in motion by means of the viscous forces induced by the rotation of the inner cylinder while the outer cylindrical crucible is kept at rest. It is possible to estimate the mean velocity of the liquid with respect of the solidification front, ahead of it, $\mathrm{U}^{\mathrm{l} / \mathrm{s}}$, as a function of the angular velocity of the rotating cylinder $\omega$, and of the radial position of the solidification front $\mathrm{R}_{\mathrm{L}}$ according to the following equation :

$$
\mathrm{U}^{1 / s}=\pi \times \mathrm{R}_{\mathrm{L}} \times \omega
$$

During the experiments, the temperature of the stirred melt is recorded versus time. Morever, sampling of the stirred melt or of the stirred mushy zone is realized at regular time intervals during cooling and solidification of the metal. Finally, the growth rate of $\mathrm{R}_{\mathrm{L}}$ is studied versus time.

A schematic view of the experimental set-up used by Moukassi [7] is shown in Fig. 2. The outer cylinder used for melting the alloys is a stainless steel crucible of $125 \mathrm{~mm}$ in I.D., $370 \mathrm{~mm}$ in height, and $4 \mathrm{~mm}$ in thickness; it contains about $4 \mathrm{dm}^{3}$ of lead-antimony alloy, i.e. $42 \mathrm{~kg}$ of metal. The alloy is melted in the crucible by means of a removable wire-furnace. As soon as the melt is heated up to the right temperature, the furnace is lowered and the outer wall of the crucible is thermally insulated ; then, the water-cooled inner cylinder is immersed to the position of $310 \mathrm{~mm}$ below the free surface of the melt. This cylinder is rotated at speeds of $100,200,300,400,500$, or 600 rotations per minute $(\mathrm{t} / \mathrm{min})$ respectively. Sampling of the melt is achieved every minute. The following quantities are measured in the metal sucked during each sampling : surface density of crystals, mean radius of the crystals, solid fraction. The main observations made by Moukassi on two different lead based alloys containing $2 \%$ and $4 \%$ of antimony respectively (Pb-2Sb; Pb-4Sb) are illustrated in Fig. 3 and 4 [6]. Fig. 3 (left) shows that the number of crystals increases rapidly with time for the $4 \mathrm{Sb}$ alloy and that this number is very dependent on the stirring intensity. Both the growth rate and the sensitivity to the stirring intensity of the number of crystals are much smaller for the $2 \mathrm{Sb}$ alloy (Fig. 3 right). On the other hand, the mean radius of the equiaxed crystals increases more rapidly versus time in the case the $2 \mathrm{Sb}$ alloy than in the case of the $4 \mathrm{Sb}$ alloy. These observations are consistent with the idea that the number and the size of crystals are controlled by the competition of two major phenomena : the fragmentation of dendrites arms of columnar and/or equiaxed crystals which results in the increase of the number of equiaxed crystals and the coarsening of the equiaxed crystals in the stirring fluid flow which results in the increase of their mean size.

The fragmentation appears to be easier for the high $\mathrm{Sb}$ alloy whereas the coarsening seems to be easier for the low Sb alloy. Even more interesting are the results which concern the relationship between the solid fraction in the stirred mush and the temperature. Fig. 4 shows that, at a given temperature, for both alloys, the solid fraction increases with the stirring intensity. Morever, equiaxed crystals have been observed in the liquid even at temperatures slightly higher than the liquidus temperature. This surprising result can be understood in the frame of a theory of the formation of the equiaxed zone based on the mechanism of the fragmentation of secondary arms of dendrites of the columnar zone. In summary, since some equiaxed crystals may be present in an overheated melt due to this mechanism of fragmentation, the description of the formation of the equiaxed zone under stirring conditions must take into account the following elementary phenomena : the fragmentation of columnar dendrites, the partial (or complete) remelting (or redissolution) of equiaxed crystals, and the coarsening and/or fragmentation of equiaxed crystals. Some recent experimental work on the effect of flow interactions with dendritic mushy zones carried out on transparent materials corroborates the conclusion that the mechanism underlying the grain refinement is the dendritic fragmentation initiated through capillary "pinching" [12]. On the other hand, a 3-D probabilistic modelling of equiaxed solidification in the presence of convection by Charbon et al. [13] demonstrates clearly that the grain movement due to the fluid flow affects the grain size distribution. Other phenomena, such as the effect of the stirring on the cooling rate of the melt, might affect also the formation of the equiaxed zone if controlled by a nucleation mechanism as proposed by Durand [9]. However, it is thought here that the mechanism of heterogeneous nucleation (on substrates which would exist in the liquid whatever the stirring state of the melt would be) does not account completely for the observations reported in the literature, including those of N'Guyen Thanh [8] whereas the fragmentation theory does. 


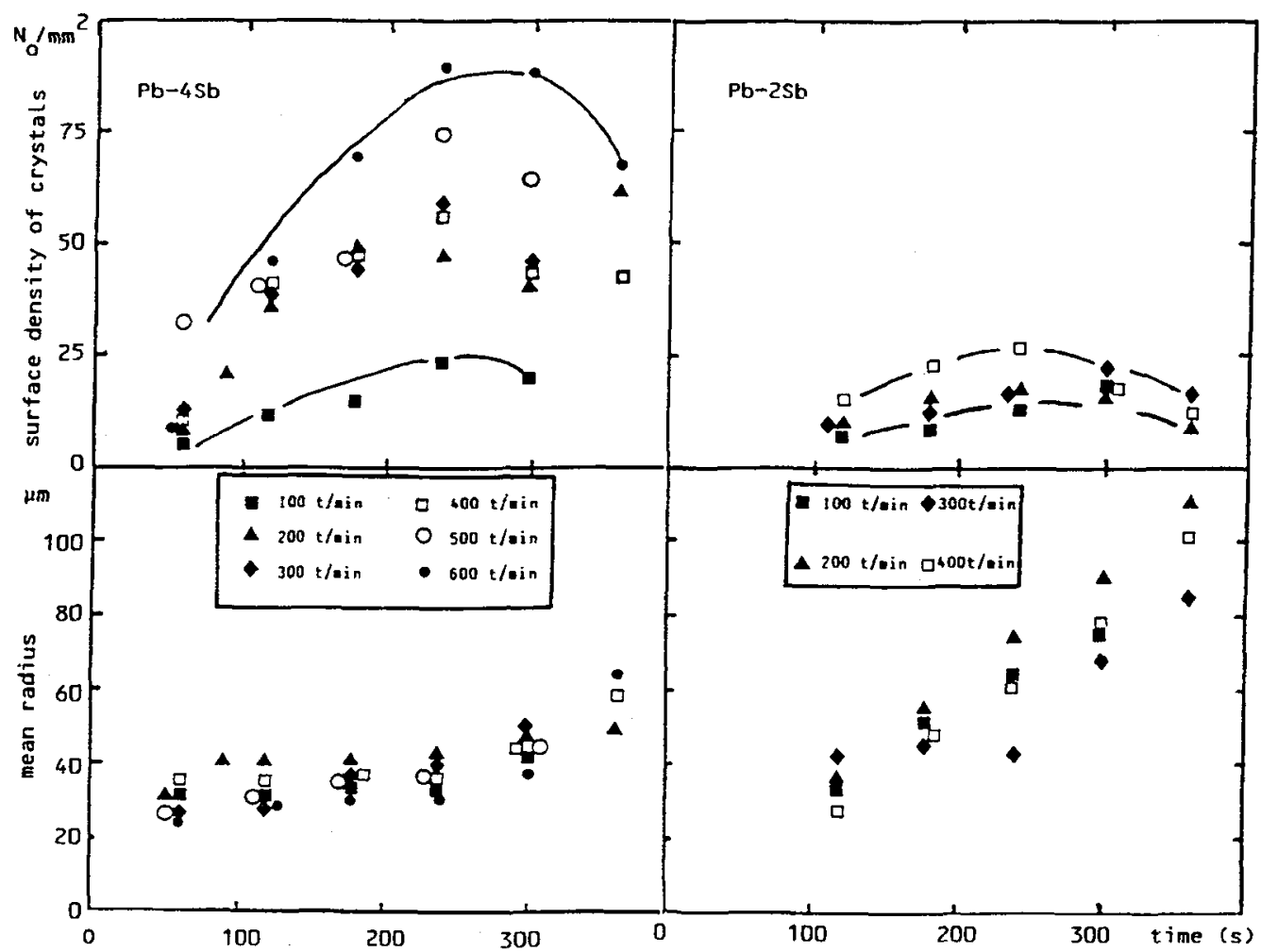

Fig. 3: Changes with time of the number of equiaxed crystals per unit surface and of their mean radius. Effects of the intensity of stirring ( $\mathrm{t} / \mathrm{min}=$ rotations per minute) and of the antimony content $(4$ or $2 \%)$

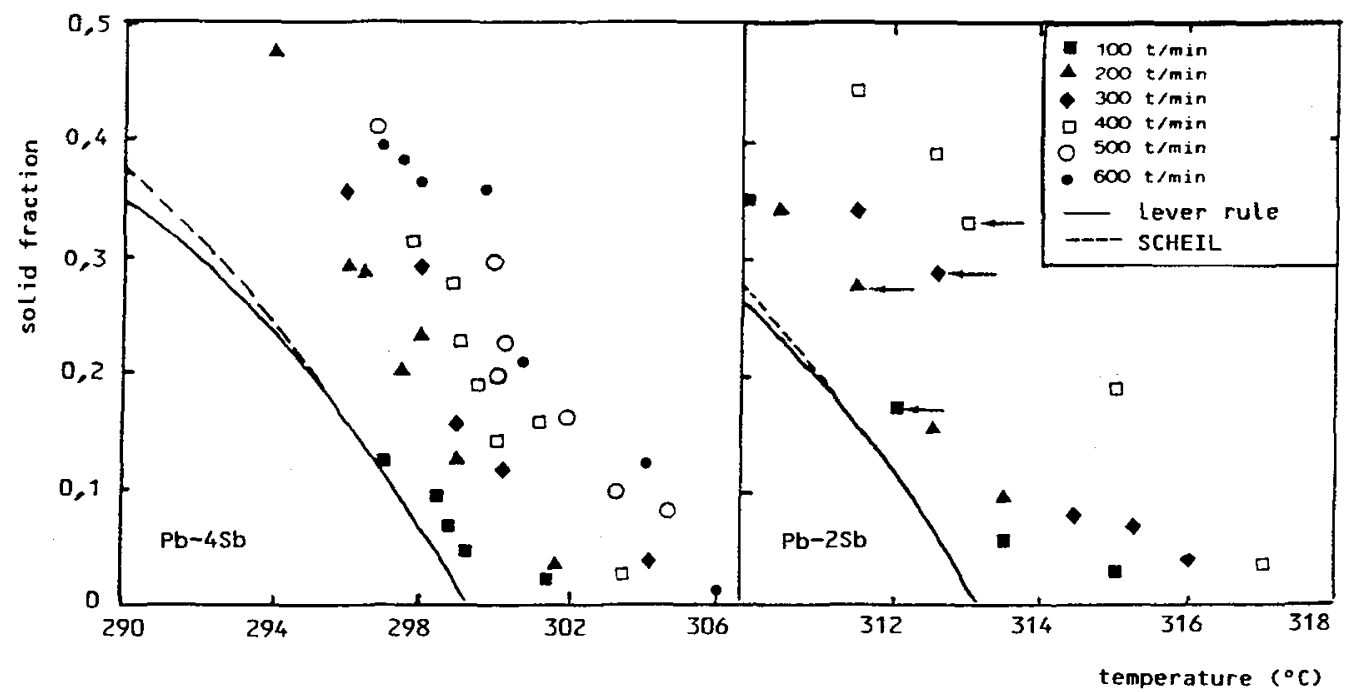

Fig. 4 : Experimental relationship between the solid fraction of equiaxed crystals in the stirred melt and the temperature. Effects of the intensity of stirring and of the antimony content . 


\section{FORMATION OF FRECKLES DURING DIRECTIONAL SOLIDIFICATION OF NICKEL BASE} ALLOYS

"Freckles" is a general term which designates macroscopic defects which appear in remelted ingots or directionally solidified castings of several alloys, including nickel base superalloys. It looks like narrow vertical channels of small segregated equiaxed grains within large zones of columnar dendritic grains. It was recognized early that freckles formation was related to segregation of light alloying elements as Smeltzer reported in 1959 that it was possible to suppress freckles by lowering the silicon level in an iron base refractory alloy [14].

Since 1970, several experimental studies have been carried out to state the effects of the main variables on the formation and characters of freckles : alloy chemistry, thermal conditions, angle between gravity and solidification direction, rotation of casting, etc. Except for the pioneer work of Giamei et al. [15], most of the studies devoted to metallic alloys were carried out on low melting point alloys [16-18]. A few of them reported that the severity of the longitudinal macrosegregation along directionally solidified samples was related to the presence of freckles. Direct observation of the formation of freckles was also made with transparent aqueous or organic systems [19-22]. Such experiments were especially useful to study the interactions between the fluid flow in the bulk liquid and the birth and growth of channels in the mushy zone during directional solidification of dendritic alloyed crystals.

Considerable progress in understanding macrosegregation and freckles formation has become possible since Flemings and coworkers published their classical papers on these subjects [23]. Because the liquid composition varies spatially with temperature within the mushy zone, any flow other than that parallel to an isotherm must alter the local composition; flow down the temperature gradient with a speed greater than that required to feed the solidification shrinkage results in negative segregation, whereas a speed that is less, or in the opposite direction, results in positive macrosegregation. In the case of freckling, the main origin for fluid flow both in the bulk liquid and in the mushy zone is recognized to be the effect of microsegregation on the local density of interdendritic liquid in the mushy zone and of liquid at the dendritic solidification front. From this viewpoint, freckling has several common characteristics with A segregates in ingots, as firstly understood qualitatively by Mc Donald and Hunt [24].

There is no discussion about the driving force which causes the freckling phenomenon : it is the buoyancy force when the solutal term counteracts the thermal one in the expression of this force:

$$
\operatorname{g} \times \operatorname{grad} \rho^{1}=\operatorname{gx} \rho^{1} \times\left(\beta_{w} \times \operatorname{grad} w^{1}+\beta_{T} \times \operatorname{grad} T\right)
$$

where $\mathbf{g} \quad$ is the gravity vector

$\mathrm{p}^{\mathrm{l}} \quad$ is the liquid density

$\mathrm{w}^{\mathrm{l}} \quad$ is the solute mass fraction in the liquid

$\beta_{\mathrm{W}} \quad$ and $\beta_{\mathrm{T}}$ are two expansion coefficients depending on the alloy.

Usually the thermal coefficient $\beta_{\mathrm{T}}$ is negative. Moreover, for most of the alloys, $\mathrm{dw} / \mathrm{dT}$ is negative in the mushy zone. Therefore the solutal coefficient $\beta_{\mathrm{w}}$ must be negative for the solutal component of the buoyancy force to compete against the thermal one during a directional solidification from the bottom to the top of a casting.

The influence of processing conditions (temperature gradient and solidification rate) on the occurrence of freckles is diversely interpreted. Some authors focuse on a "freckle potential" defined as follows to explain that freckling occurs below a threshold of temperature gradient for a given alloy composition [19]:

$$
\Delta \Psi=\frac{g}{G} \frac{\beta_{w}}{\beta_{T}} \frac{\left(T_{L}-T_{E}\right)\left(w_{E}-{ }^{o} w\right)\left(\rho_{L}-\rho_{E}\right)}{G^{2}}
$$


where $T_{L}$ means the liquidus temperature

$\mathrm{T}_{\mathrm{E}}$ the eutectic temperature

$o_{W}$ the alloy composition

$W_{E}$ the eutectic

$\rho_{L}$ the density of the liquid alloy

and $\quad \rho_{E} \quad$ the density of the eutectic liquid

To explain the effect of growth rate on freckling, the same authors introduced a critical time $\Delta t^{*}$ which would be required to produce a detectable freckle trail. The freckles are then supposed to appear if the local solidification time is larger than the critical value $\Delta \mathrm{t}^{*}$, thus if the solidification rate is lower than the following value :

$$
v<\frac{T_{L}-T_{E}}{\Delta t^{*} \cdot G}
$$

More recently, Pollock et al. [25] reported that the formation of freckle type defects in directionally solidified nickel based single crystal alloys was related to some critical dendrite arm spacing. Furthemore, they claimed that transitions in solidification behavior were consistent with changes in dendrite morphology and they proposed to characterize the operative regimes of grain defect formation in terms of dendrite arm spacings.

In order to decide if the occurrence of freckling is controlled by the processing conditions rather than by the microstructural features, numerical simulation is useful. As a matter of fact, it is impossible to change experimentally the processing conditions without changing the dendrite microstructure. On the other hand, it is possible to simulate by means of calculations the effects of $G$ and $v$ on the freckling, independently of the effect of the dendrite spacing, for instance. Some results are presented here to illustrate this interesting way to use the numerical simulation as a tool for a deeper understanding of the physics of freckling.

\section{NUMERICAL SIMULATION OF FRECKLES FORMATION}

Recent studies have shown the possibility of simulating numerically the formation and the early development of freckles during solidification of binary alloys [26-27]. These numerical simulations are made by solving simultaneously, and in a fully coupled manner, equations of heat, mass and momentum transfers ; they are based on mathematical models where the overall solidifying heterogeneous system (liquid+mush+solid) is described as a single continuous equivalent medium. Such a mathematical and numerical tool has been used by the authors to simulate the effect of several variables on the segregation pattern of the as-cast metal : alloy composition, temperature of the chill, and initial superheat [28]. The physical situation is assumed to be two-dimensional ; it consists of an initially liquid binary alloy contained in a rectangular mold, the bottom of which is kept to a constant temperature, $T_{B}$, which is lower than the nominal solidus temperature of the alloy. The other boundaries of the mold are adiabatic. The alloy begins to solidify from the bottom by forming a fully solid layer plus a columnar dendritic mushy zone. The solidification proceeds upward until the initially molten alloy is completely solidified.

The overall heterogeneous solidifying casting has been described as a single continuous equivalent medium as far as mass, solute mass, momentum and energy transport are concerned according to Beckermann's and Viskanta's ideas [29]. The equations of conservation of mass, solute mass, momentum and energy are solved in a fully coupled manner under the following assumptions :

1) the fluid flow is not turbulent ;

2) solidification shrinkage as driving force for fluid flow is neglected ;

3) the solid phase does not move ;

4) solid and liquid phases are in local complete equilibrium : solute diffuses perfectly in solid and liquid phases on a microscopic or dendritic scale ;

5) diffusion of solute at a macroscopic scale is neglected ;

6) liquid density is constant everywhere except in the buoyancy term of the momentum equation. 
The set of equations of conservation is solved with a finite volume method using the algorithm SIMPLE [30]. Since all transfers are coupled, an iterative solving procedure is used. Details relative to the mathematical model and to the numerical scheme have already been presented by the authors in connection with simulations of the formation of macrosegregation in heavy steel ingots [31].

Calculations were performed for binary nickel base Ni-Al alloys, containing 5,10, or 13 wt pct. aluminum respectively, the thermophysical properties of which are reported in Table $\mathrm{I}$.

Table I : Thermophysical properties used for calculations.

\begin{tabular}{|l|r|}
\hline \multicolumn{1}{|c|}{ property } & \multicolumn{1}{|c|}{ value } \\
\hline Density $\left(\mathrm{kg} \mathrm{m}^{-3}\right)$ & 6890. \\
Thermal expansion coefficient $\left(\mathrm{K}^{-1}\right)$ & $-1.410^{-4}$ \\
Solutal expansion coefficient $\left(\mathrm{wt} \mathrm{pct}^{-1}\right)$ & $-1.4510^{-2}$ \\
Kinematic viscosity $\left(\mathrm{m}^{2} \mathrm{~s}^{-1}\right)$ & $7.310^{-7}$ \\
Dendrite arm spacing $(\mu \mathrm{m})$ & 40. \\
Thermal conductivity $\left(\mathrm{W} \mathrm{m}^{-1} \mathrm{~K}^{-1}\right)$ & 20. \\
Heat capacity J kg ${ }^{-1} \mathrm{~K}^{-1}$ & 418. \\
Phase change temperature of the pure substance $\left({ }^{\circ} \mathrm{C}\right)$ & 1453. \\
Liquidus slope $(\mathrm{K}$ wt pct.- & -4.53 \\
Partition coefficient & 0.87 \\
\end{tabular}

The computational domain consists of a rectangular region of width $\mathrm{W}=30 \mathrm{~mm}$ and height $\mathrm{H}=$ $90 \mathrm{~mm}$. It has been discretized with a uniform mesh of 45 elements in the horizontal direction and 45 elements in the vertical direction. The same time-step has been used for every calculations : $\Delta \mathrm{t}=0.4 \mathrm{~s}$. The alloy is initially all liquid and homogeneous in composition and temperature. The initial temperature is fixed between about $1400^{\circ} \mathrm{C}$ and $1600^{\circ} \mathrm{C}$ in order to study the effect of superheat (between about 0 ${ }^{\circ} \mathrm{C}$ and $200^{\circ} \mathrm{C}$ ). The side walls are insulated and the bottom temperature is constant and imposed in the range : $900-1380^{\circ} \mathrm{C}$ to study the effect of cooling intensity. From the viewpoint of fluid flow, the liquid is initially at rest. "Non slip" conditions are imposed at all boundaries.

It is worth to notice that the dendrite arm spacing was fixed to a constant value, $40 \mu \mathrm{m}$, in all the calculations whatever the local thermal conditions for solidification were.

Results related to the effects of the cooling intensity on freckling were obtained by comparing simulations of casting experiments $\mathrm{N}^{\circ} 1,2$ et 3 with decreasing bottom temperatures : $1380^{\circ} \mathrm{C}, 1300^{\circ} \mathrm{C}$, and $900^{\circ} \mathrm{C}$ respectively, everything else being kept constant. Decreasing the temperature of the bottom of the ingot, $\mathrm{T}_{\mathrm{B}}$, results in increasing definitely the rates of solidification and increasing slightly the temperature gradients. Fig. 5 shows the patterns of the final positive segregations resulting from the simulated experiments $N^{\circ} 1,2$, and 3. Since the levels of grey are the same for the three cases, comparison between patterns affords a direct information on the predictable effects. Decreasing the bottom temperature, thus increasing the cooling intensity, results in decreasing noticeably the intensity of segregations both at the top of the ingot and in the channels. Moreover, the onset of the last most active channels occurs closer to the top as cooling intensity is increased.

From a practical and macroscopic point of view, longitudinal segregation profile between the bottom and the top of ingots is an important characteristics of the as-cast metal. To figure out what was the quantitative effect of several parameters on the overall longitudinal macrosegregation, concentration profiles along vertical axes located at equal distance from two neighbour channels have been plotted on Figure 6 for experiments selected here. Figure 6 shows how longitudinal segregation is influenced by the cooling intensity. A low bottom temperature $\mathrm{T}_{\mathrm{B}}\left(\mathrm{N}^{\circ} 2\right.$ or 3$)$ imposes an almost zero segregation whereas a high $\mathrm{T}_{\mathrm{B}}\left(\mathrm{N}^{\circ} 1\right)$ results in a definite longitudinal segregation. 


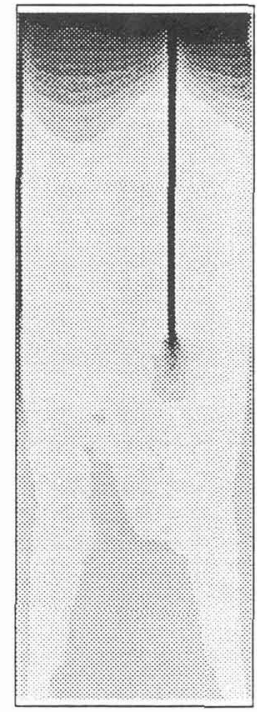

$\mathrm{N}^{\circ} 1$

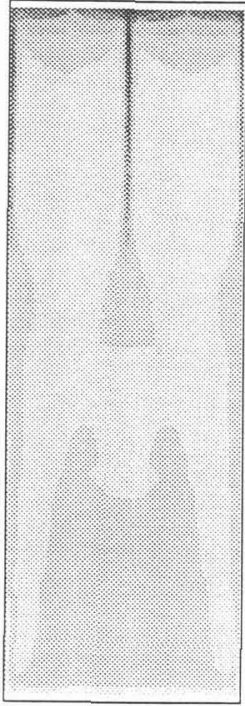

$\mathrm{N}^{\circ} 2$

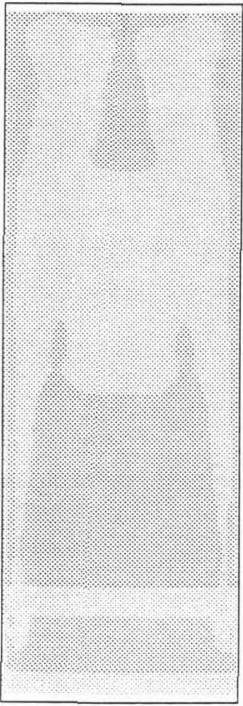

$\mathrm{N}^{\circ} 3$

Fig. 5 : Final segregation patterns, expressed in $\Delta w=w-{ }^{\circ}$ resulting from the numerical simulation of experiments $\mathrm{N}^{\circ} 1$ to 3 . Influence of the intensity of chilling: $\mathrm{T}_{\mathrm{B}}=1380,1300$ and $900^{\circ} \mathrm{C}$ for experiments 1,2 , and 3 respectively (from ref. [28].

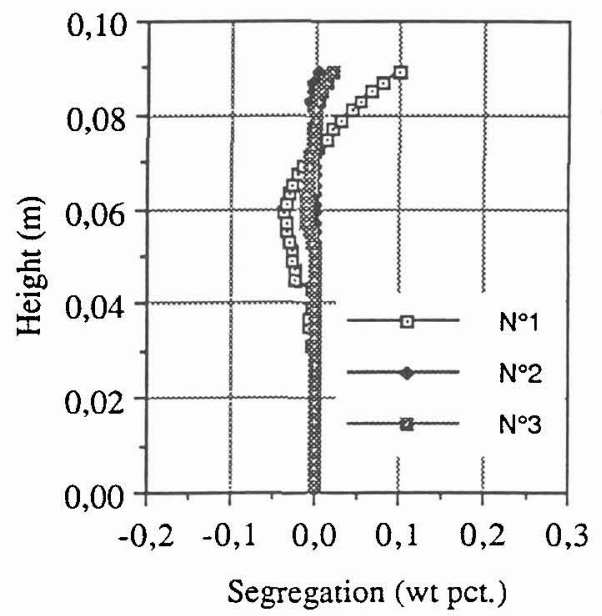

Fig. 6 :Influence of the intensity of chilling on the segregation profile along a vertical axis located at equal distance from two neighbour channels (from ref. [28].

Results illustrated by Figs. 5 and 6 show that both the meso and the macrosegregation can be suppressed by changing the heat transfer conditions, i.e. lowering the bottom temperature $\mathrm{T}_{\mathrm{B}}$, therefore increasing $\mathrm{v}$ and $\mathrm{G}$, but keeping the dendrite arm spacing constant. It can be concluded that the thermal conditions have a definite effect on the occurrence of freckles in directionally solidified ingots of nickel based alloys whatever the dendrite arm spacing is. 


\section{CONCLUSIONS}

Two examples have been selected here to illustrate the variety and the complexity of the interactions of the fluid flow and the solidification of alloys.

In the case of the continuous casting of steel, the main phenomena which explain the effects of stirring on the formation of the equiaxed zone are likely : the fragmentation of dendrite arms in the columnar front, the coarsening of bits of equiaxed crystals, eventually the remelting or the redissolution of the crystals in superheated regions of the melt. The fragmentation process along the columnar front is controlled by the morphology of the columnar dendrites together with the microsegregation and the capillary pinching. Heat transfer is thought to have only an indirect effect through the partial control of the dendrite morphology.

On the other hand, in the case of freckling during directional solidification, heat transfer conditions have been demonstrated to be critical for the control of the meso and macrosegregation due to channelling in the mushy zone, whatever the dendrite arm spacing is. The morphology and size of dendrites in the columnar zone might affect however the occurrence of misoriented grains due to dendrite fragmentation along the fluid flow channels.

\section{$\underline{\text { References }}$}

[1] J.P. Birat, J. Choné, Ironmaking and Steelmaking 10 (6) (1983) 269.

[2] J.P. Birat, P. Neu, J.C. Dhuyvetter, M. Janneau, Proc. AIME Steelmaking Conf. 65 (1982) 36.

[3] G. Lesoult, P. Neu, J.P. Birat, in "Metallurgical Applications of Magnetohydrodynamics", Ed. H.K. Moffatt et al., Publ. The Metals Society (1984) 164.

[4] A. Etienne, in "F. Weinberg Int. Symp. on Solidification Processing", Ed. J.E. Lait et al., Pergamon Press (1990) 108.

[5] H. Fredriksson et al., Scand. J. Metallurgy 15 (1986) 127.

[6] M. Moukassi, Ph D Thesis INPL Nancy (Nov. 1988).

[7] M. Moukassi, G. Lesoult, Proceedings of the $6^{\text {th }}$ Int. Iron and Steel Congress (1990) Nagoya, ISIJ Vol.1, p 567.

[8] L. N'Guyen Thanh, Ph D Thesis INPG Grenoble (Dec. 1989).

[9] F. Durand, ibidem [7] p 559.

[10] T. Takashashi, I. Hagiwara, J. Jap. Inst. Metals 29 (1965) 1152.

[11] T. Takashashi, I. Hagiwara, K. Ichikawa, Trans. ISIJ 12 (1972) 412.

[12] C.J. Paradies, G.T. Kim, M.E. Glicksman, R.N. Smith, in "Modeling of Casting, Welding and Advanced Solidification Processes VI", Ed. T.S. Piwonka et al. MMMS (1993) 309.

[13] Ch. Charbon, A. Jacot, M. Rappaz, special issue of Materials Science and Engineering - EMRS Spring Meeting Strasbourg (1993) to be published.

[14] C.E. Smeltzer, Jr., The Iron Age, (sept. 10) (1959), 188.

[15] A.F. Giamei and B.H. Kear, Metall. Trans., 1 (1970), 2185.

[16] N. Streat and F. Weinberg, Metall. Trans., 5 (1974), 2539.

[17] J.R. Sarazin and A. Hellawell, Metall. Trans., 19A (1988), 1861.

[18] L. Wang et al., Metall. Trans., 19A (1988), 2687.

[19] S.M. Copley et al., Metall. Trans., 1 (1970), 2193.

[20] S. Asai and I. Muchi, Trans. ISIJ, 18 (1978), 90.

[21] A.K. Sample and A. Hellawell, Metall. Trans., 15A (1984), 2163.

[22] J.R. Sarazin et al., in Nature and Properties of Semi Solid Materials, Edited by J.A. Sekhar and J. Dantzig, The Minerals, Metals \& Materials Society, (1991), 143.

[23] R. Mehrabian et al., Metall. Trans., 1 (1970), 1209.

[24] R.J. McDonald and J.D. Hunt, Trans. AIME, 245 (1969), 1993.

[25] T.M. Pollock, W.H. Murphy, E.H. Goldman, D.L. Uram, J.S. Tu, in "Superalloys $1992 "$ Ed. S.D. Antolovich et al., MMMS (1992) 125.

[26] A.C. Fowler, IMA J. Applied Math., 35 (1985), 159.

[27] J.C. Heinrich et al., Metall. Trans., 20B (1989), 883.

[28] H. Combeau, G. Lesoult, ibidem [12] 201.

[29] C. Beckermann and R. Viskanta, Int. J. Heat Mass Transfer, 31 (1988), 35.

[30] S.V. Patankar, Num Heat Transfer and Fluid Flow, Hemisphere, Washington DC, (1980).

[31] H. Combeau et al., in "Heat Transfer 90", First Int. Conf. on Advanced Computational Methods in Heat Transfer, Ed. L.C. Wrobel, Springer Verlag, 3 (1990), 79. 